\title{
Assessment of biomass energy potential for SRC willow woodchips in a pilot scale bubbling fluidized bed gasifier
}

\author{
Irfan Ul Hai ${ }^{\mathrm{a}}$, Farooq Sher ${ }^{\mathrm{b}}$, Aqsa Yaqoob ${ }^{\mathrm{a}, \mathrm{c}}, \mathrm{Hao} \mathrm{Liu}^{\mathrm{a}}$
}

a. Faculty of Engineering, University of Nottingham, Nottingham NG7 2RD, UK

b. School of Mechanical, Aerospace and Automotive Engineering, Faculty of Engineering, Environmental and Computing, Coventry University, Coventry CV1 2JH, UK

c. Department of Chemistry, University of Agriculture, Faisalabad 38000, Pakistan

\begin{abstract}
The current study investigates the short rotation coppice (SRC) gasification in a bubbling fluidized bed gasifier (BFBG) with air as gasifying medium. The thermochemical processes during combustion were studied to get better control over the air gasification and to improve its effectiveness. The combustion process of SRC was studied by different thermo-analytical techniques. The thermogravimetric analysis (TGA), derivative thermogravimetry (DTG), and differential scanning calorimetry (DSC) were performed to examine the thermal degradation and heat flow rates. The product gas composition $(\mathrm{CO}$, $\mathrm{CO}_{2}, \mathrm{CH}_{4}$ and $\mathrm{H}_{2}$ ) produced during gasification was analyzed systematically by using an online gas analyzer and an offline GC analyzer. The influence of different equivalence ratios on product gas composition and temperature profile was investigated during SRC gasification. TG/DTG results showed degradation occur in four stages; drying, devolatilization, char combustion and ash formation. Maximum mass loss $\sim 70 \%$ was observed in devolatilization stage and two sharp peaks at $315-500{ }^{\circ} \mathrm{C}$ in TG/DSC curves indicate the exothermic reactions. The temperature of gasifier was increased in the range of $650-850{ }^{\circ} \mathrm{C}$ along with the height of the reactor with increasing equivalent ratio (ER) from
\end{abstract}

\footnotetext{
** Corresponding author. School of Mechanical, Aerospace and Automotive Engineering, Faculty of Engineering, Environmental and Computing, Coventry University, Coventry, CV1 2JH, UK. E-mail addresses: Farooq.Sher@ coventry.ac.uk, Farooq.Sher@gmail.com (F. Sher).
} 
0.25 to 0.32 . The experimental results showed that with an increment in ER from 0.25 to 0.32 , the average gas composition of $\mathrm{H}_{2}, \mathrm{CO}, \mathrm{CH}_{4}$ decreased in the range of 9-6\%, 16-12\%, 4-3\% and $\mathrm{CO}_{2}$ concentration increased from $17-19 \%$ respectively. The gasifier performance parameters showed a maximum high heating value (HHV) of $4.70 \mathrm{MJ} / \mathrm{m}^{3}$, Low heating value (LHV) of $4.37 \mathrm{MJ} / \mathrm{m}^{3}$ and cold gas efficiency (CGE) of $49.63 \%$ at 0.25 ER. The ER displayed direct effect on carbon conversion efficiency (CCE) of $95.76 \%$ at $0.32 \mathrm{ER}$ and tar yield reduced from 16.78 to $7.24 \mathrm{~g} / \mathrm{m}^{3}$ with increasing ER from 0.25 to 0.32 . All parametric results confirmed the reliability of the gasification process and showed a positive impact of ER on CCE and tar yield.

Keywords: Renewable energy; Biomass gasification; Bubbling fluidized bed; SRC willow chips; Thermo-analytical techniques; Product gas composition and tar yield. 


\section{Introduction}

The growing energy demand from coal and natural gas leads to a shortage of fossil fuel because of time constraint for its reproducibility and environmental issues regarding fossil's fuel emission: the greenhouse effect and global warming in the near future. Biomass is a preferable energy source due to abundantly available, easily storable, transportable, and independent of location and climate [1]. Biomass is considered as the fourth renewable, potentially sustainable source of alternative energy which meets $14 \%$ of the total world's primary energy consumption [2]. It was reported that $4.8 \mathrm{G}$ tons of oil equivalent biomass will be used as a source of fuel in 2050 [3]. Biomass is a carbon-neutral energy source with zero $\mathrm{CO}_{2}$ emissions [4, 5]. During the combustion of biomass fuels, useful energy and the same amount of $\mathrm{CO}_{2}$ is released which was absorbed during the plant life cycle and emissions of $\mathrm{SO}_{2}$ and $\mathrm{NOx}$ are extremely low. Therefore, biomass is a good choice as a clean and environment friendly fuel after coal and natural gas [6].

The selection of biomass fuel is dependent on ash/ residue contents, moisture contents, cellulose/lignin ratio, carbon and volatiles, alkali metal contents, calorific value and moisture contents $[7,8]$. The process of ignition becomes difficult when the biomass moisture contents are more than 30\% [9]. Thermochemical conversion (combustion, pyrolysis and gasification) while biochemical conversion (fermentation and anaerobic digestion) are two main available technologies for biomass conversion into energy [10]. Biomass gasification converts solid carbonaceous biomass into gaseous fuels under controlled conditions with limited oxygen and produces a mixture of hot gases that are cleaned and can be utilized in power generation through gas turbine [11, 12]. The product gas of biomass gasification is considered most important due to direct use for power generation, but it requires suitable operating conditions and product gas 
cleaning strategies for final applications[13]. The producer gas holds; $\mathrm{H}_{2}, \mathrm{CO}, \mathrm{CO}_{2}, \mathrm{CH}_{4}, \mathrm{~N}_{2}$, water vapours and other types of impurities i.e. alkali compounds, chlorine, sulphur, tar, nitrogen, char and particulates [14]. Syngas $\left(\mathrm{CO}+\mathrm{H}_{2}\right)$ produced during biomass gasification is an eco-friendly fuel for electricity generation and considered a versatile technology [15]. Hydrogen gas is an efficient clean energy carrier for the production of electricity that can be produced from biomass gasification. $\mathrm{CH}_{4}$ and other liquid fuels can also be generated from syngas [1].

Many researchers have reported the studies on the effect of gasifier type, the composition of bed material, gasification temperature, equivalent ratio (ER), biomass feedstock type on the gasification and product gas composition [16]. A variety of designs and technologies were developed in combustion plants, gasifiers, and pyrolysis plants. Fixed bed gasifiers and fluidized bed gasifiers technologies were largely investigated for biomass gasification by a number of scientists in past decades [17]. The disadvantage of the fixed bed gasifiers is the difficulty in maintenance of the constant operational temperature [16]. Furthermore, the bubbling fluidized bed biomass gasification is largely preferred over other technologies because of high conversion efficiency, uniform temperature profile in the reactor that is suitable for gas-solid interactions.

Karmakar et al. [18] have studied the rice husk gasification in FBG to examine the influence of temperature variation from $650-725^{\circ} \mathrm{C}$ with air as a gasifying medium at $0.25 \mathrm{ER}$. Their results suggested that with temperature increment, $\mathrm{H}_{2}$ and $\mathrm{CO}$ were increased in the range of 17.2218.49\% and 24.89-26.59\%, while $\mathrm{CO}_{2}$ and $\mathrm{CH}_{4}$ were decreased from $14.92-12.61 \%$ and 2.621.96\%. The improvement in CCE from $71.51-75.82 \%$ with temperature was due to high conversion of unburned particles at high temperatures. The study of Subbaiah et al. [19] explored 
the gasification potential of groundnut shell (GNS) in FBG in $650-900{ }^{\circ} \mathrm{C}$ at 0.20 to $0.40 \mathrm{ER}$. They investigate the air-steam gasification that suggested the gas yield of $\mathrm{CO}$ and $\mathrm{H}_{2}$ was increased with a rise in temperature and maximum CCE was $83.4 \%$ at $800{ }^{\circ} \mathrm{C}$. The maximum $\mathrm{HHV}\left(6.9 \mathrm{MJ} / \mathrm{Nm}^{3}\right)$ was observed at $0.30 \mathrm{ER}$ and $800{ }^{\circ} \mathrm{C}$ temperature.

Singh et al. [19] reported the gasification process of ground Nutshell (GNS) at 0.29-0.33 ER. The gasification temperature was $650-800{ }^{\circ} \mathrm{C}$ while air was used as a gasifying agent. They used conventional charcoal in bed heating. The most optimum ER reported for GNS gasification was 0.31 that was showed $5.74 \%$ of $\mathrm{CH}_{4}, 91 \%$ of $\mathrm{CCE}$ and $71.8 \%$ of CGE. Both the above studies of GNS suggested the optimum ER's were in the range of 0.30-0.31 and Singh et al. [20] study reported highest CCE at 0.31 ER. Sarker et al. [21] reported the alfalfa pellets gasification in FBG that was found attractive fuel for grid power generation. They studied gasification at 0.25 and 0.30 ER and their results demonstrated the increment in bed temperature with an increase in ER. In addition, the CGE of $39 \%$ and the gas yield of $1.6 \mathrm{Nm}^{3} / \mathrm{kg}$ was observed. The LHV of $4.2 \mathrm{MJ} / \mathrm{Nm}^{3}$ was obtained that indicate the alfalfa is promising biomass in terms of energy conversion. Most of the experimental parameters were enhanced by increasing the input air at a constant feed rate.

Maglinao Jr. et al. [22] analysed the CCE, heating values and gasification efficiencies of three feedstock high tonnage sorghum, beef cattle manure and cotton gin trash in BFG in the temperature range of $730-790{ }^{\circ} \mathrm{C}$ and $\mathrm{ER}(0.3-0.5)$. They observed high carbon content and high efficiencies for tonnage sorghum. The optimum $\mathrm{H}_{2}$ generation was found at $780{ }^{\circ} \mathrm{C}$ and $0.40 \mathrm{ER}$. The steam, as well as air gasification of sawdust, was performed to investigate the thermodynamic effect. Air was proven as an efficient gasifying agent that showed higher energy efficiency than steam 
gasification. The efficiency was continuously decreased by increasing ER when either steam and air used as a gasifying medium [23]. The product gas composition of rice husk gasification in a BFBG has been investigated previously, the composition of $\mathrm{H}_{2}, \mathrm{CH}_{4}$, and $\mathrm{CO}$ was decreased with an increase in ER, but the composition of $\mathrm{CO}_{2}$ was increased. The appropriate ER value reported for its gasification was 0.2-0.3. [24]. Mohammed et al. [25] performed gasification in FBG using empty fruit bunch (EFB) as biomass and air as a gasifying agent in the temperature range of 700$1000{ }^{\circ} \mathrm{C}$. The $\mathrm{H}_{2}$ and $\mathrm{CH}_{4}$ concentrations were increased from 10.27 to 38.02 and 5.84 to $14.72 \%$ respectively with increasing temperature. The concentration of $\mathrm{CO}$ was increased from $21.87-$ $36.36 \%$, while the concentration of $\mathrm{CO}_{2}$ decreased from $63-12 \%$. The gas yield was reached to $\sim 92 \%$ at $1000{ }^{\circ} \mathrm{C}$.

Sciazko et al. [26] reported that air gasification is mostly performed in $726-926{ }^{\circ} \mathrm{C}$ temperature range in FBGs, while during air-steam gasification the increase in hydrogen generation, increased the produced syngas with a high calorific value that helps to decrease the mixing of hydrocarbon and tar. High molecule weight tar components were observed at high temperature in $100 \mathrm{~kW}$ dual fluidized bed gasifier (DFBG). The tar molecules were primarily treated within gasifier and secondary treatment was outside the gasifier by different techniques; baffled filters, rotating particle separators, fabric filters, electrostatic filters, ceramic filters, and scrubbers etc. [27]. The torrefaction effect on syngas quality of SRC chips was investigated in BFBG. Syngas quality was investigated by tar concentration and gas yield. About $47 \%$ reduction in tar yield has been reported from BFB gasification of SRC with steam and air as a gasifying medium [28]. Another attempt was made when SRC willow gasification was tried in a down-draft gasifier but results showed that willow chips were not gasified due to bridging within the hopper. Afterwards, a stirring bar was 
employed to prevent bridging and gasification was done successfully. The product gas collection was unsuccessful, therefore could not be further analyzed [29].

To the best of our knowledge, there is limited information available on short rotation coppice gasification in BFBG. Therefore, this study is designed to fill the gap in knowledge concerning the gasification of SRC willow woodchips and thermochemical assessment. Detailed thermogravimetric analysis and effect of different operating variables such as ER and temperature on product gas compositions of SRC gasification are studied. SRC willow chips were selected due to resprouting capacity after coppice, ease of harvesting, ease of propagation, broad genetic breeding and high yield, which is able to fulfil the energy demands by high power generation [30]. The single planting of SRC can be harvested more than seven times due to resprouting ability [31]. The experiments were performed to investigate SRC gasification in a BFBG using air as a gasifying agent focusing on temperature profiles and product gas composition under different parameters. The biomass degradation behaviour was examined by TG/DTG to estimate the heat flow and decomposition characteristics of biomass. In addition, the effect of ER on temperature was studied to explore exothermic and endothermic reaction during gasification. The HHV, LHV, CGE and CCE were calculated to examine the performance of gasifier. This is a comprehensive study that discloses the optimum and best operating conditions for SRC willow gasification in a bubbling fluidized bed gasifier. Furthermore, this study also covers the detailed product gas composition analyses to examine the SRC gasification and gasifier performance evaluation. 


\section{Experimental}

\subsection{Biomass characteristics}

SRC willow woodchips (size: $3-10 \mathrm{~mm}$ ) from a local SRC willow grower were selected for gasification in bubbling fluidized bed biomass gasifier (BFBBG). The proximate and ultimate analysis of SRC willow woodchips was performed using TGA Q500 and is given in Table 1 [7, 32]. The TGA/DTG analysis was done to determine the thermal behaviour and degradation characteristics of biomass [33]. The TGA/DSC analysis was performed to examine the heat flow per unit mass with temperature under an air atmosphere. The comparison of burning profiles of TG/DTG and TG/DSC was used to determine the stages of thermal degradation of biomass [34].

\subsection{Experimental setup of Gasifier}

The bubbling fluidized bed biomass gasifier (BFBBG) is schematically represented in Fig. 1 consists of a biomass feeding hopper, screw feeder, fluidized bed gasification reactor, cyclone, gas cooling unit, tar removal unit (a mop fan unit, a biomass/ char bed), electrically heated combustor, an air supply/ preheating system and data acquisition devices. In BFBG, the gasifying reactor can be virtually divided into the bed (gas-solid reaction) zone and the freeboard (gas phase reaction) zone. The bubble formation within the bed of bubbling fluidized bed biomass gasifier increased the heat transfer rate of bed material and mixing efficiency of fuel particles and gasifying agent. The main gasifier consists of a stainless-steel reactor had dimensions of $108 \mathrm{~mm}$ diameter and height of $1800 \mathrm{~mm}$. The fluidization air was entered through a blower. The flow rate of air was controlled by a rotameter. The air was fed into gasifier reactor by an air distribution plate with a pore size of $100 \mu \mathrm{m}$ and thickness of $10 \mathrm{~mm}$ which also allows preheating up to required gasification temperature $\left(700-900{ }^{\circ} \mathrm{C}\right)$ through electric pre-heater [35]. 
The SRC willow woodchips were fed into the combustor by a screw feeder just above the air distribution plate. The biomass feeding unit supported the desired feed rate of woodchips by using a screw auger and timed stirrer. The auger is used to transfer woodchips from the hopper into the reactor by an inverter. The inverter was used to control the frequency of the feeder motor. To prevent from backflow of biomass and sand particle into the feeding unit, a small amount of air was also introduced through feeder hopper. The temperature profiles of the gasification reactor were continuously monitored by placing eight K-type thermocouples at different distances from the distribution plate. These thermocouples are labelled as T1, T2, T3, T4 (bottom and middle thermocouples) and T5, T6, T7 and T8 (upper thermocouples) which are located at -5, 9, 17, 25, 45, 74, 105 and $150 \mathrm{~cm}$ height above from the distribution plate. T1 was located in the air chamber under the distribution plate, while $\mathrm{T} 2-\mathrm{T} 5$ measures the gasification temperature variation occurring in dense bed zone and T6-T8 are uppermost thermocouples set at freeboard region of reactor, monitoring the temperature variation of the gas exit.

The reactor was equipped with pressure sensors at different heights to examine the fluidization conditions of the bed. The bubble formation, rising and bursting of bed material in the reactor was observed by increasing the fluidization air flow rate that is shown in Fig. 2. The gas particles usually move upward from bed at a minimum fluidization velocity that is less than $5 \mathrm{~m} / \mathrm{s}$. The rising of gas from bed create bubbles that maintain bubble emulsion and fluidization state at the bed. After this dense bed, a freeboard region is present that reduces the supercritical velocity and return the particles towards the bed region. In this way, bed material almost remains fixed [36]. The pressure difference is closely checked at dense bed region and freeboard region to detect any 
sign of defluidization and agglomeration during gasification. If an abrupt change in pressure difference recorded across dense bed region and reactor temperature, it means defluidization.

This research was designed to focus on product gas composition and temperature profiles. All the above mentioned tests were performed to avoid defluidization and agglomeration during gasification $[37,38]$. At the exit point of the reactor, a cyclone is fitted for the removal of particles from product gas to achieve high efficiency. The ash particles are collected in an ash pot from the bottom of the cyclone. After cooling, product gas by gas cooler it is introduced into the mop fan cleaning unit. The centrifugal fan casing mop with $70 \mathrm{~mm}$ fibre length and $0.4-0.6 \mathrm{~mm}$ diameter of each fibre is used for gas circulation, de-dusting of contaminated product gas stream and efficient removal of gaseous contaminants. The efficiency of particles removal is improved by a water spray, fibre number and fibre arrangement. An on-line gas analyzer (ABB Easy Line analyzer) is fitted at the end of a gasifier to continuously determine the product gas $\left(\mathrm{CO}, \mathrm{CO}_{2}, \mathrm{CH}_{4}\right.$ and $\mathrm{H}_{2}$ ) composition. The analyzer calibration was done with standard gas samples. For comparison, the product gas was also analyzed in an off-line offline gas chromatography (GC) analyser. All of the measured and processed data such as product gas profile and temperature are continuously monitored by computerized systems.

\subsection{Gasifier operating conditions}

The operational parameters of gasifier and gasification process are characterized by equivalence ratio, temperature profile along with the height of the reactor, feeding rate and gas concentrations at the exit. The constant biomass flow rate was achieved through repeated calibration after regular intervals by checking the amount of biomass flow from the hopper to the gasification reactor in a specific time through the auger. The timed stirrer was adjusted as $5 \mathrm{sec} / \mathrm{min}$ to the hopper. Timed 
stirrer and feeder confirmed the stable feed rate to achieve steady product gas and temperature profile. An auto stirrer was used to stirrer the biomass constantly to prevent bridging and to improving the gas quality [39]. The reliable sampling for reproducible results of product gas analysis was obtained by using different rotation speed of auger i.e., 10, 11 and $12.5 \mathrm{~Hz}$. The auger speed controls the feeding rate of wood chips. The inverter of gear motor controls the auger rotational speed.

The gasification was performed at three different ERs; 0.25, 0.29 and 0.32 in BFBG. The fluidization and gasification process are examined by a set of thermocouples and pressure sensors. Compressed air was used as a fluidization medium at room temperature. The operating conditions for biomass gasification of willow chips are given in Table 2. When desired temperatures have obtained in the gasification reactor, the biomass is introduced into the gasifier and air was fed accordingly to the selected ER values. A small amount of air $(3 \mathrm{~L} / \mathrm{min})$ at room temperature and 1 atm pressure was introduced into the hopper to prevent any backward diffusion of biomass and sand particles. The ER was modified by adjusting the gasification airflow rats; 45,65 and $80 \mathrm{~L} / \mathrm{min}$ for $0.25,0.29$ and 0.32 respectively. After gasification initiation, a steady state condition was achieved in the reactor after about 30 min of feeding and all variables were continuously monitored. All parameters in the rig (pressure, temperature and product gas composition analysis) were recorded by the data acquisition system.

\subsection{Estimation of Gasifier's performance}

The performance of BFBG was investigated by calculating gas yield, cold gas efficiency (CGE), Carbon conversion efficiency (CCE), high heating value (HHV) and low heating value (LHV) of product gas. The gasifier performance was monitored by comparing the gasification process at 
different ERs $(0.25,0.29$ and 0.32$)$. These calculations were performed by using following equations $1-5[6,21]$.

a. HHV

$\mathrm{HHV}=\left(\mathrm{H}_{2}\right.$ conc. in product gas $* \mathrm{HHV}$ of $\left.\mathrm{H}_{2}\right)+(\mathrm{CO}$ conc. in product gas $+\mathrm{HHV}$ of $\mathrm{CO})+\left(\mathrm{CH}_{4}\right.$ conc. in product gas $* \mathrm{HHV} \mathrm{CH}_{4}$ )

b. LHV

$$
\mathrm{LHV}_{\text {gas }}=\quad \sum \mathrm{Vi}^{*} \mathrm{LHVi}
$$

where $\mathrm{Vi}=\%$ composition of gas component in the product gas

$\mathrm{LHVi}=$ lower heating value of the individual gas component

c. Gas yield

Total gas yield $=$ Amount of $\mathrm{N}_{2}$ fed to the gasifier $* \mathrm{~N}_{2}$ concentration in the product gas

$=\mathrm{N}_{2}\left(\mathrm{~m}^{3} / \mathrm{h}\right) *\left(100-\sum \mathrm{V}_{\mathrm{gi}}\right)$

where $\quad V_{\mathrm{gi}}=\mathrm{N}_{2}=$ Air fed into the gasifier $\left(\mathrm{m}^{3} / \mathrm{h}\right) * \mathrm{~N}_{2}$ concentration in product gas

d. Cold gas efficiency

Cold gas efficiency was calculated by the following equation:

$$
\operatorname{CGE}(\eta)=\frac{\text { Gas yield } * \text { LHVgas }}{\text { Biomass feeding rate } * \text { LHVbiomass }} * 100
$$

e. Carbon conversion efficiency

$$
\mathrm{CCE}(\%)=\frac{12(\mathrm{CO} 2+\mathrm{CO}+\mathrm{CH} 4+2.5 \mathrm{CnHm}) * \text { Gas yield } * 100 \%}{22.4 * 298 / 273}
$$

\section{Results and discussion}

\subsection{Thermogravimetric analysis}

The Thermogravimetric analysis (TGA) was performed to investigate the chemical reactions and thermal stability of biomass with quantitative measurement of weight loss over a specific temperature range. Fig. 3 shows the sample weight loss and derivative mass loss with temperature 
by using air as a reacting medium. Blue curve indicated four degradation stages; drying, devolatilization, char combustion and ash formation [40]. Red line shows the DTG curve. The initial mass loss (up to $\sim 9 \%$ ) was observed in the drying stage at temperatures of $26-125{ }^{\circ} \mathrm{C}$ that is associated with the removal of moisture. SRC willow chips showed $10 \%$ moisture content that was determined by ultimate analysis as given in Table 1 . This moisture content is most suitable for gasification. The presence of higher moisture content needs more energy for the drying process during gasification [41].

Most of the volatile components, tar, gases and char produced during thermal decomposition of biomass (devolatilization) and almost 70\% mass loss of initial weight occurred in devolatilization zone $\left(126-363{ }^{\circ} \mathrm{C}\right)$ region [33]. The ignition temperature $\left(\mathrm{T}_{\mathrm{ign}}\right)$ represents the onset of devolatilization stage and known as an active pyrolysis region, which was started at $259{ }^{\circ} \mathrm{C}$. The peak temperature of the devolatilization region was $337{ }^{\circ} \mathrm{C}$ that is known as glass transition temperature $\left(\mathrm{T}_{\mathrm{g}}\right)$ as derived from TGA/DTG curves [42]. The mass loss of $\sim 27 \%$ was observed in the temperature region of $363-513{ }^{\circ} \mathrm{C}$ because of char combustion. Finally, the ash formation was observed in the temperature range of $513-850^{\circ} \mathrm{C}$ containing $\sim 1 \%$ biomass sample.

The DTG curves showed two peaks; first sharp and strong peak was observed in $261-374{ }^{\circ} \mathrm{C}$ temperature range having a maximum rate of mass loss $35 \% / \mathrm{min}$ at $338{ }^{\circ} \mathrm{C}$. This region revealed the degradation of carbon content and devolatilization of biomass. The second peak in the DTG curve indicates the char combustion that was obtained in the secondary pyrolysis zone (275-510 ${ }^{\circ} \mathrm{C}$ ) with maximum mass loss rate $\sim 11 \% / \mathrm{min}$ at $483{ }^{\circ} \mathrm{C}$. Beyond $510{ }^{\circ} \mathrm{C}$, the DTG curve showed a slow rate of mass loss $\sim 1 \% / \mathrm{min}$ because degradation is almost completed in this region and only 
char residue left behind. Thermal degradation behaviour of biomass showed that pyrolysis of hemicellulose usually occurred at a temperature below than $350{ }^{\circ} \mathrm{C}$. While cellulose pyrolysis occurred in temperature ranges $250-500{ }^{\circ} \mathrm{C}$. There was no sharp peak beyond $500{ }^{\circ} \mathrm{C}$ because most of the biomass have already degraded and only lignin shows some thermal stability [34, 42, 43]. Nyakuma et al. [44] studied thermochemical assessment of the empty fruit bunch (EFB) by heating in the temperature range of $50{ }^{\circ} \mathrm{C}$ to $900{ }^{\circ} \mathrm{C}$ at $10^{\circ} \mathrm{C} / \mathrm{min}$ heating rate. TGA results suggested four stages of biomass thermal decomposition and $70 \%$ weight loss was observed in devolatilization stage at $325^{\circ} \mathrm{C}$ peak temperature.

\subsection{Differential scanning calorimetry}

Fig. 4 shows TG/DSC curve heat depicted the heat flow per unit mass during exothermic and endothermic reactions with temperature variation. The main reactions that take place during biomass gasification are given in Table 3. In accordance with Le Chaetlier's principle, endothermic products and exothermic reactants are favoured at high temperature. At initial, drying and heating of biomass require heat and endothermic reactions are favoured. Two sharp peaks were observed in the temperature range of $315-500{ }^{\circ} \mathrm{C}$ which showed the exothermic reaction of gasification.

Most of partial char combustion and devolatilization occurs in this region, which releases a large amount of heat due to the combustion of unburned particles and release of volatiles. At this stage, TGA also confirmed the breakdown of larger chains of hydrocarbon into smaller chains, and thermal decomposition of fuel into the gaseous product [34]. The heat flow curve suggested that as the gasification proceeds with the rise of temperature, endothermic reactions such as Boudourad reaction, water gas shift reaction and methane reforming reaction were favoured. The gas products are then reformed through these reactions [45]. Zhao et al., [46] reported the detail pyrolysis of 
corn straw and soybean straw with TG/DTG and TG/DSC analysis in a fixed bed reactor. Their results found four pyrolysis stages and temperature increased with increasing heat rate that produces high char yield.

\subsection{Effect of ER on gasifier temperature}

The temperature of gasification is considered important in determining the composition and yield of the product gas. Temperature is not an independent factor in gasification. The temperature profile of gasifier is linked to the amount of air available (ER), therefore, both are considered important parameters for gasification. The temperature profiles of gasifier are controlled by ER; with an increase in ER the amount of air introduced into the reactor is also increased which enhances the oxidation rate of biomass. This enhanced oxidation rate increases the heat release and carbon conversion content which results in an increment in the temperature of gasifier reactor. Fig. 5 presents the influence of ER on the temperature profiles of the gasifier reactor (T2-T8). By increasing ER from 0.25 to 0.32 , the temperature distribution in all regions such as; dense board and freeboard showed an increase to their maximum values of $817,812,785,777,778,782,548$ ${ }^{\circ} \mathrm{C}$ for $\mathrm{T} 2$ to $\mathrm{T} 8$ respectively. Therefore, higher ER value showed that most of the partial combustion occurs in the gasifier reactor due to increased temperature.

This increasing temperature with ER also continued distinctive differences between all sensors at a different height. This increment in temperature was due to more air entered into the reactor in oxidation zone and promote combustion that has increased the temperature of gasifier [21]. The results indicated that when ER is increased from 0.25 to 0.29 then 0.32 , the temperatures at all thermocouple in the reactor were smoothly increased. As the high temperature is achieved in the gasifier, a series of endothermic reactions including drying, char combustion with exothermic 
reactions (devolatilization) started which describe the temperature behaviour along with the height of the reactor. At the exit of the gasifier reactor, the temperature is decreased because of heat losses and endothermic char combustion and tar cracking [47]. This trend is also confirmed by the heat flow curve shown in Fig. 4. Nevertheless, there is a decrease in temperature at $-5 \mathrm{~cm}$ distance (T1) from the distribution plate because of introducing an additional air without preheating into the reactor. [48]. The highest temperature observed in the oxidation zone while the lowest temperature was recorded in the upper portion of gasifier in the pyrolysis region [49]. The high temperature favoured water gas shift reactions which further promote steam methane reforming reaction [50]. By comparing the effect of different ER value, the higher temperature was observed with $E R=0.32$ which indicate the increase in temperature by increasing ER value.

Temperature is considered the most important factor that affects the gasification process. González-Vázquez et al., [51] estimated the effect of temperature on pine kernel shell gasification, product gas concentrations, gas yield and CGE. The results concluded that the rise in temperature from 700 to $900{ }^{\circ} \mathrm{C}$ favoured high $\mathrm{H}_{2}$ production and best gasifier performance. From literature, it is observed that higher temperature is responsible for higher hydrogen concentration and low tar content because of thermal tar cracking reactions. Due to this more volatiles were released at high temperature and increased the overall gas yield. The BFBG is considered a promising option for hydrogen generation. Therefore, hydrogen generation through thermochemical route such as biomass gasification in BFBG is remarkable technology. The desired gasification temperature is achieved by partial combustion. The yield of producer gas, CGE and tar contents in the syngas are dependent on the temperature of gasification [52]. Perez et al. [53] investigated the thermodynamic and fluid-dynamic analysis of sugarcane bagasse in BFBG. Geldart's types of particles were used 
to examine the fluidization parameter in gasification. The results showed the $4.56 \mathrm{MJ} / \mathrm{Nm}^{3}$ of $\mathrm{LHV}$ and $0.8-1.21 \mathrm{~mm}$ of ideal particle size was suggested for large scale gasification.

\subsection{Effect of equivalence ratio on product gas compositions}

The equivalence ratio (ER) has a greater effect on concentrations of product gas and calorific value of syngas that directly affects the performance parameters of gasification [15]. The ER was varied from 0.25 to 0.32 to examine the effect of ER on product gas composition. The gasification airflow rate was changed from 45 to 65 and then $80 \mathrm{~L} / \mathrm{min}$ to obtain a selected range of ER in the gasifier. These experiments were performed with feeding rates $1920.9,2126.8$ and $2469.6 \mathrm{~g} / \mathrm{h}$ for $0.32,0.29$ and 0.25 ER respectively. The stable and constant biomass feeding is used for biomass gasification because it is considered important for reliable product gas sampling and their analysis. The feeding process and product gases are affected by moisture content, auger rotational speed, dimensions of biomass particle. The size of SRC willow was 3-10 mm that provides excellent heat transfer rate $[54,55]$.

\subsubsection{Online analysis of product gas compositions}

ER values distinguish the combustion and gasification process. ER value less than 1 is considered for gasification and optimum range from $0.2-0.4$ has been reported for biomass gasification. If ER value is taken below 0.2 then it produces unnecessary char, syngas with low heating value and incomplete gasification occurred. While ER values above 0.4 also cause a problem, such as extreme production of combustion products $\left(\mathrm{CO}_{2}, \mathrm{H}_{2} \mathrm{O}\right)$ [50]. The product gas found from air gasification of biomass is usually composed of some combustible and incombustible gases. The analysis of these products $\left(\mathrm{CO}, \mathrm{CO}_{2}, \mathrm{CH}_{4}\right.$, and $\left.\mathrm{H}_{2}\right)$ was done by online gas analyzers. Four runs of gasification were performed at each ER value to check the repeatability and reliability of the 
experiments and product gas values. Fig. 6 gives the distribution of product gas composition at various ERs monitored by the on-line gas analyzer as well as GC analyzer. Only slight differences in product gas composition were observed for each run, which confirmed the reliability and reproducibility of the experiments.

The product gas concentrations with online gas analyzer are presented in Table 4. At 0.25 ER, the average concentrations of $\mathrm{CO}, \mathrm{CO}_{2}, \mathrm{CH}_{4}$ and $\mathrm{H}_{2}$ were $16.98,17.49,4.43$ and $9.95 \%$ respectively. The concentrations observed at 0.29 ER were $14.20,18.19,3.94$ and $8.26 \%$ for $\mathrm{CO}, \mathrm{CO}_{2}, \mathrm{CH}_{4}$ and $\mathrm{H}_{2}$ respectively. While the compositions of product gas at ER 0.32 were $12.72,19.21,3.88$ and $6.30 \%$ for $\mathrm{CO}, \mathrm{CO}_{2}, \mathrm{CH}_{4}$ and $\mathrm{H}_{2}$ respectively [56]. These values show that with increasing ER value from 0.25 to 0.32 , the concentration of $\mathrm{CO}, \mathrm{CH}_{4}, \mathrm{H}_{2}$ decreased while $\mathrm{CO}_{2}$ increased. The product gas composition obtained from Fig. 6(a-c) indicates that the concentration of $\mathrm{CO}$ decreased from 16.98 to $12.72 \%$ with an increment in ER from 0.25 to 0.32 . The concentrations of $\mathrm{CH}_{4}$ and $\mathrm{H}_{2}$ were also decreased from $4.43-3.88 \%$ and $9.95-6.30 \%$ respectively by increasing ER in the selected range. The decrease in $\mathrm{H}_{2}$ concentration was observed because of the water gas shift reaction in which $\mathrm{H}_{2}$ consumption rate was greater as compared to $\mathrm{H}_{2}$ formation rate [56]. While the decreased concentration of $\mathrm{CH}_{4}$ from $3-4 \%$ with increasing ER was due to methanation.

However, the $\mathrm{CO}_{2}$ composition was found to increase from 17.49 to $19.21 \%$ by increasing ER from 0.25 to 0.32 . By increasing $\mathrm{ER}$, more air entered into the reactor, $\mathrm{CO}$ and $\mathrm{CH}_{4}$ were burned with $\mathrm{O}_{2}$ and formed $\mathrm{CO}_{2}$ due to excessive availability of air. The results of $\mathrm{CO}, \mathrm{H}_{2}$ and $\mathrm{CH}_{4}$ compositions displayed opposite trend to $\mathrm{CO}_{2}$ composition in product gas profile of gasification. These trends were due to different ER values because ER indicates the quantity of actual air 
available for volatile formation and gasification of fuel. During gasification, gas products react with oxygen and produce $\mathrm{CO}, \mathrm{CH}_{4}, \mathrm{H}_{2}$ and $\mathrm{CO}_{2}$ gases. These gaseous products are formed by series of reaction including carbon reaction, Boudouard reaction, water gas shift reaction or methanation reactions as already depicted in Table 3 [52].

Therefore, low concentration of combustible gases $\left(\mathrm{CO}, \mathrm{CH}_{4}\right.$ and $\left.\mathrm{H}_{2}\right)$ was found at high ER value and diminished the product gas quality. The low ER favoured endothermic reactions that are char $+\mathrm{CO}_{2}$ and water gas shift reactions. Therefore, more char and $\mathrm{CO}_{2}$ used in these reactions which lower the $\mathrm{CO}_{2}$ composition [57]. Considering the trends of gas concentrations with decreasing ER, the maximum increment is obtained for $\mathrm{CO}$ concentration while the small increment is found in $\mathrm{CH}_{4}$ concentration. The increment in $\mathrm{H}_{2}$ concentration is seen smaller than the increment in $\mathrm{CO}$ concentration. Likewise, the increment in $\mathrm{CO}$ concentration is greater than the decrease in $\mathrm{CO}_{2}$ concentration with decreasing ER. Similar results were reported by Sarker et al. [21] which showed the increase in $\mathrm{CO}_{2}$ concentration when the ER value was increased from 0.20-0.35.

Though, the current study showed enhanced $\mathrm{CH}_{4}$ concentration nearly $4-3 \%$, which is greater than $\mathrm{CH}_{4}$ concentration (2.6-2.0\%) of wheat straw pellet gasification as reported Sarker et al. [21]. Kim, Yang et al. [48] reported that a decrease in the concentration of $\mathrm{H}_{2}$ and $\mathrm{CO}$ was due to water gas shift reaction. By increasing ER from 0.25 to 0.32 , the $\mathrm{H}_{2}$ product gas was decreased by approximately $9-6 \%$ due to the dominant oxidation reaction at higher ER value because oxidation in gasification reactor dominates and produce less $\mathrm{H}_{2}$ gas [58]. The higher concentration of $\mathrm{CO}$ in the product gas was also reported by Makwana, Joshi et al. [59] which was due to the lower value of ER. They gasified rice husk and char of rice husk by varying the ER from 0.30 to 0.38 . The 
higher $\mathrm{CO}(18 \%)$ and $\mathrm{H}_{2}(5.6 \%)$ composition were found at low ER due to endothermic steam reforming reaction. In the present study, the gasifying medium was air which increased oxidation reaction by producing $\mathrm{CO}_{2}$ from the utilization of $\mathrm{CO}$ and $\mathrm{O}_{2}$. The air also promotes complete oxidation of fixed carbon component and oxygen resulting CO concentration drops. More residual carbon is produced by increasing gasifying medium and combustion due to pyrolysis in steam gasification which increases the carbon conversion efficiency.

\subsubsection{Gas chromatography analysis of product gas composition}

The product gas composition analysis was also carried out through Gas chromatography (GC), to check the reliability and reproducibility of the online gas analyzer. When all gasification parameters become stable, the four sampling bags of 0.5 litre were filled with product gas for offline GC analysis. This analysis was performed with the same ER's as used for online analysis. The composition of product gas measured at the inlet of combustor was comprised of $\mathrm{CO}_{2}, \mathrm{CO}$, $\mathrm{H}_{2}, \mathrm{CH}_{4}$ and a small amount of $\mathrm{O}_{2}$. This gas composition was important for partial oxidation. Table 4 shows GC analysis of product gas compositions at different ERs.

The GC analysis showed $16.64,17.99,4.67,8.96 \%$ concentrations of $\mathrm{CO}, \mathrm{CO}_{2}, \mathrm{CH}_{4}$ and $\mathrm{H}_{2}$ respectively at 0.25 ER. Karatas, Akgun et al. [52] reported pilot-scale gasification of natural wood at the same ER 0.25 as reported by the present designed study. They reported the $5 \%$ concentration of $\mathrm{CH}_{4}$ that is nearly similar to the current study of SRC at this ER. The concentrations observed at $0.29 \mathrm{ER}$ were $14.50,18.16,4.06$ and $8.31 \%$ for $\mathrm{CO}, \mathrm{CO}_{2}, \mathrm{CH}_{4}$ and $\mathrm{H}_{2}$ respectively. While the compositions of product gas at ER 0.32 were $12.29,18.24,4.22$ and $6.53 \%$ for $\mathrm{CO}, \mathrm{CO}_{2}, \mathrm{CH}_{4}$ and $\mathrm{H}_{2}$ respectively [56]. The results of product gas concentration by GC analysis are in clear agreement with the online analyser. The GC analysis results showed that $\mathrm{CO}_{2}$ increased from 17.99 
to $18.24 \%$ with increasing ER $(0.25-0.32)$. This is because the oxygen supply was dominant as of increasing air feeding that burns volatile component of biomass by producing more $\mathrm{CO}_{2}$. This gas also dilutes the other combustible gases therefore, at higher ER less concentration of $\mathrm{H}_{2}, \mathrm{CH}_{4}$, and $\mathrm{CO}$ is produced. At $0.32 \mathrm{ER}$, the concentration of $\mathrm{CH}_{4}$ was low (4.22\%) but it can significantly change the gas heating values [60].

The product gas composition results of online analyses and off-line GC analysis are already given in Table 4. The results of product gas obtained from both analyzers are then compared to check the efficiency of analyzers. The comparison of product gas profile at 0.25 ER is shown in Fig. 6(a). Their results showed the one-factor difference in $\mathrm{H}_{2}$ concentration of $\mathrm{GC}$ and online analysis. The $\mathrm{H}_{2}$ concentration recorded by GC analyser was $8.96 \%$, but online analyser recorded $9.95 \%$, that is marginally different. However, all other remaining product gas composition showed stability from both analyses $[50,57]$. The comparison of product gas at 0.29 ER is represented in Fig. 6(b). The results indicated a slight difference in $\mathrm{CH}_{4}$ composition. The $\mathrm{CH}_{4}$ concentration recorded by GC analyser was $4.06 \%$, however, online analyser recorded 3.94\%. While the other gas compositions were almost the same from both analysers. At ER 0.32, a comparison of product gas profiles from GC and online analyzers is given in Fig. 6(c).

The comparison confirmed the quantitative composition of product gases that shows only one factor difference in $\mathrm{CO}_{2}$ concentration while other gas compositions almost same and showed uniformity from both analysers. This comparison was effective and confirmed the efficiency of both analysers. Therefore, the qualitative and quantitative results of product gas at different ER 
from both GC and online analysers are in excellent agreement with each other and confirmed the efficiency of analysers and the energy profile of SRC willow.

\subsection{Gasifier performance evaluation}

The performance of bubbling fluidized bed gasifier was examined in terms of product gas concentrations and carbon conversion. A set of desirable efficiency parameters were investigated to check the efficiency of converting input mass into synthesis gas product with reduction of tar.

\subsubsection{Bed temperature and tar yield}

The effect of ER on average bed temperature and tar yield was studied. Fig. 7 confirms that ER values have a positive linear correlation with average bed temperature and negative linear correlation with tar yield. When the bed temperature increased from 776 to $817^{\circ} \mathrm{C}$, a decrease in tar yield from 16.78 to $7.24 \mathrm{~g} / \mathrm{m}^{3}$ by was noticed by increasing ER from 0.25 to 0.32 respectively. Therefore, the increment in the ER in the gasifier enhanced the average bed temperature about $\sim 40$ ${ }^{\circ} \mathrm{C}$, which is considered effective for gasification. This increment in bed temperature with ER was due to more air availability for oxidation reaction that promotes heat release.

The high bed temperature also favoured $\mathrm{H}_{2}$ and $\mathrm{CO}$ concentration in accordance with Le Chatelier's principle, which depicted that reactant substance in exothermic reactions and product substance in endothermic reactions favoured at a higher temperature. Therefore, endothermic steam gasification reaction is strengthened at a higher temperature with increasing ER [18]. The increase in bed temperature with ER was also due to the uniform size of bed particles, which was easily deposited on the bed surface. These particles were burnt easily when coming in contact with bed surface and release heat. Air can easily circulate throughout the reactor due to pressure fluctuation in the reactor and bed surface that improved fluidization and combustion behaviour 
and increased the bed temperature [20]. Improper fluidization may cause agglomeration and failure of the gasification process [38]

The increase in carbon conversion efficiency and bed temperature with the increase of ER from 0.25 to 0.32 improves the tar decomposition. This is because of thermal cracking and reforming reactions [50]. ER played an important role in tar content and their properties. By increasing ER from 0.25 to 0.32 , air availability is increased which decreased the tar yield from 16.78 to 7.24 $\mathrm{g} / \mathrm{m}^{3}$ as given in Fig. 7. This decreasing trend was due to more combustion of hydrocarbons and tar cracking reaction at high ER. The tar cracking reactions including steam gasification reaction as well as reforming reaction decrease the tar yield. The partial combustion reaction increased the temperature of the reactor, which favoured char gasification with high conversion rate and reduces the tar yield [37]. However, higher ER improves the bed temperature that causes tar decomposition and decreased the tar yield and this reduction in tar yield is very important for gasification.

\subsubsection{Evaluation of LHV and gas yield}

The gasification parameters such as LHV, Cold gas efficiency (CGE) and gas yield were investigated to examine the gasifier performance efficiency. The CGE is the percentage of LHV of biomass converted into LHV of product gas. CGE is also called gasification efficiency. As the ER value is varied from 0.25 to 0.32 , all gasification parameters (gas yield, CGE, LHV, CCE) were also changed. Fig. 8 shows a decrease in LHV and an increase in the gas yield of product gas with increasing ER values. The LHV was decreased from 4.37 to $3.67 \mathrm{MJ} / \mathrm{m}^{3}$ by increasing ER from 0.25 to 0.32 . This was due to less production of combustible gases $\left(\mathrm{CO}\right.$ and $\left.\mathrm{H}_{2}\right)$ which favoured a decrease in LHV. The LHV was decreased due to exothermic water gas shift reaction as well as dilution of syngas with air nitrogen [12]. The HHV was decreased from 4.70 to 3.95 
$\mathrm{MJ} / \mathrm{m}^{3}$ while the LHV was also decreased with increasing ER, this trend was also observed in the previous studies. Karatas, Akgun et al. [52] reported that the LHV of walnut shell and pistachio shell was decreased by increasing ER from 0.19 to 0.37 . It can be seen in Fig. 8 that the gas yield increased from 3.93 to $4.55 \mathrm{~m}^{3} / \mathrm{h}$ by increasing ER from 0.25 to 0.32 respectively.

The increment in gas yield is because of increment in the gasifying medium that is caused by increasing ER. That is the reason the gas yield is varied with a gasifying agent. The temperature becomes higher in oxidation zone at high ER, which favoured high volatilization of biomass and char gasification. Moreover, further increment in temperature, increase the gas yield due to the steam reforming reaction. Meng et al. [61] reported the sawdust gasification with different gasifying agents. The gas yield was changed from 2.11 to $2.41 \mathrm{~m}^{3} / \mathrm{h}$ with increment in the ER from 0.20-0.30. The amount of gas yield obtained in the present study is more than gas yield reported for sawdust. This increment in gas yield could be due to biomass type and operating conditions of gasifier but the overall trend of gas yield with ER is in accordance with the literature.

\subsubsection{Determination of CGE and CCE}

At the selected ERs $0.25,0.29$ and 0.32 , the CGE varied from 49.63, 47.89 to $46.43 \%$ respectively also shown in Fig. 9. Cold gas efficiency was influenced by ER. CGE examines how much heating content of biomass is used to convert the feedstock into product gas. By increasing ER, the low heating value (LHV) of producer gas decreased because of excessive oxidation of feed and more inert nitrogen is also introduced with air which diminished the quality of product gas [62]. Therefore, this rise in air availability diminished the product gas quality due to the large oxidation reaction of biomass. 
The decreasing LHV of product gas showed the total energy conversion into product gas is decreased, which decreases the CGE [39]. Similar findings and trends of CGE and LHV with ER have been reported by Hamad, Radwan [63], Ahmed et al. [64] and Guo et al. [49]. The CCE is the percentage of gasified carbon content to the total carbon content in the added feed [18]. In an ideal system only, most of the biomass is to be transformed into desirable product gas mixture and other secondary particulates. However, in case of woodchips biomass gasification, carbon, oxygen and hydrogen in the feedstock are transformed into a mixture of synthesis gas, secondary products including carbon dioxide, methane and higher gaseous hydrocarbons and other unwanted particulates such as sulfur species, particulate matter and tars. The carbon conversion calculations at different biomass feeding rate were performed by using constant gasification airflow rate (44.72 $\mathrm{L} / \mathrm{m}$ ) and during $60 \mathrm{~min}$ of feeding. The carbon conversion efficiency (CCE) was estimated at 0.32, 0.29, and 0.25 ER with $1920.9,2126.8$ and $2469.6 \mathrm{~g} / \mathrm{h}$ feeding rates respectively, that is also displayed in Fig. 9.

The results indicate that the highest carbon conversion $(95.76 \%$ ) was achieved with $1920.9 \mathrm{~g} / \mathrm{h}$ feeding rate of biomass at $0.32 \mathrm{ER}$ value. The CCE was 90.68 and $95.48 \%$ at 0.29 and $0.25 \mathrm{ER}$ respectively. By increasing ER from 0.25 to 0.32 , the CCE efficiency is varied from 95.48 to 95.76 $\%$. When ER is increased, more air is introduced into gasifier that favoured exothermic oxidation reaction. This exothermic reaction increased the temperature of the gasifier and also promotes the steam reformation that in turn increased the carbon conversion rate [50]. By increasing ER from 0.25 to 0.32 more carbon content of the biomass was converted into product gas $\left(\mathrm{CO}, \mathrm{CO}_{2}\right.$ and $\mathrm{CH}_{4}$ ) which leads to gradually increase in carbon conversion rate. Therefore, $\mathrm{CCE}$ reached its maximum value (95.76\%) at 0.32 ER. Diyoke et al. [57] also reported that CCE depends on the 
rate of oxidation of carbon particulates Therefore, CCE is increased and CGE is reduced with increasing ER from 0.25 to 0.32 .

\section{Conclusions}

In this present study, gasification characteristics of SRC willow chips were investigated using bubbling fluidized bed gasifier (BFBG) at $600-850{ }^{\circ} \mathrm{C}$ and at different equivalence ratios of 0.25 , 0.29 and 0.32 . The thermochemical investigation was done by TG/DTG and TG/DSC analysis to explore the thermal stability and degradation characteristics of biomass. Furthermore, the influence of ER on concentrations of product gas was examined by online and offline analysis. The main findings of the study are summarized as follows:

- The TGA/DTG analysis was performed to examine the thermal degradation characteristics of biomass. The highest weight loss observed in the devolatilization stage was $\sim 70 \%$ in the temperature range between 126 and $363{ }^{\circ} \mathrm{C}$. While two sharp peaks observed within the range of 315 to $500^{\circ} \mathrm{C}$ in TG/DSC curves indicate the exothermic reactions. Heat release can be utilized in power generation.

- By increasing ER, the temperature profiles of reactor increase and the highest temperature were observed in dense board region in the range of $650-850{ }^{\circ} \mathrm{C}$. The increased bed temperature with increasing ER is considered important for tar reduction and to improve the carbon conversion rate.

- An increment in ER from 0.25 to 0.32 , the GC and online analysis showed the average concentration of $\mathrm{CO}, \mathrm{CH}_{4}$ and $\mathrm{H}_{2}$ decreased in the range of $16-12 \%, 4-3 \%$ and $9-6 \%$ respectively. In addition, the $\mathrm{CO}_{2}$ concentration increased from $17-19 \%$ in the product gas composition. This is because of more air availability for oxidation at high ER, which 
diminishes the product gas quality and lower the combustible gas concentrations. Both GC and online analysis of product gas compositions showed clear agreement with each other.

- Both the gas yield and CCE increased while LHV, CGE and tar yield gradually decreased with increasing ER from 0.25 to 0.32 . The maximum carbon conversion efficiency of 95.76\% was observed at 0.32 ER. These parameters results confirmed the reliability of the gasification process, gasifier performance and product gas composition.

- TGA and gasification results showed the high thermal stability and high carbon conversion efficiency of selected SRC willow chips. Therefore, SRC willow biomass is recommended as renewable energy fuel for the future power generation industry and for the other applications. 


\section{References}

1. Sikarwar, V.S., et al., An overview of advances in biomass gasification. Energy \& Environmental Science, 2016. 9(10): p. 2939-2977.

2. Anupam, K., et al., Preparation, characterization and optimization for upgrading Leucaena leucocephala bark to biochar fuel with high energy yielding. Energy, 2016. 106: p. 743756.

3. Williams, A., et al., Pollutants from the combustion of solid biomass fuels. Progress in Energy and Combustion Science, 2012. 38(2): p. 113-137.

4. Farzad, S., M.A. Mandegari, and J.F. Görgens, A critical review on biomass gasification, co-gasification, and their environmental assessments. Biofuel Research Journal, 2016. 3(4): p. 483-495.

5. Sher, F., et al., Experimental investigation of woody and non-woody biomass combustion in a bubbling fluidised bed combustor focusing on gaseous emissions and temperature profiles. Energy, 2017. 141: p. 2069-2080.

6. Sarkar, M., et al., Gasification performance of switchgrass pretreated with torrefaction and densification. Applied energy, 2014. 127: p. 194-201.

7. Chen, J., et al., Analysis of biomass gasification in bubbling fluidized bed with two-fluid model. Journal of Renewable and Sustainable Energy, 2016. 8(6): p. 063105.

8. Vassilev, S.V., C.G. Vassileva, and V.S. Vassilev, Advantages and disadvantages of composition and properties of biomass in comparison with coal: An overview. Fuel, 2015. 158: p. 330-350.

9. Sheth, P.N. and B. Babu, Production of hydrogen energy through biomass (waste wood) gasification. International Journal of Hydrogen Energy, 2010. 35(19): p. 10803-10810.

10. Yilmaz, S. and H. Selim, A review on the methods for biomass to energy conversion systems design. Renewable and Sustainable Energy Reviews, 2013. 25: p. 420-430.

11. IEA., World Energy Outlook 2013. 2013, IEA Publications Paris.

12. Manatura, K., et al., Exergy analysis on torrefied rice husk pellet in fluidized bed gasification. Applied Thermal Engineering, 2017. 111: p. 1016-1024.

13. Husmann, M., et al., Comparison of dolomite and lime as sorbents for in-situ H2S removal with respect to gasification parameters in biomass gasification. Fuel, 2016. 181: p. 131138.

14. Đurišić-Mladenović, N., B.D. Škrbić, and A. Zabaniotou, Chemometric interpretation of different biomass gasification processes based on the syngas quality: Assessment of crude glycerol co-gasification with lignocellulosic biomass. Renewable and Sustainable Energy Reviews, 2016. 59: p. 649-661.

15. Ruiz, J., et al., Biomass gasification for electricity generation: review of current technology barriers. Renewable and Sustainable Energy Reviews, 2013. 18: p. 174-183.

16. Couto, N., et al., Influence of the biomass gasification processes on the final composition of syngas. Energy Procedia, 2013. 36: p. 596-606. 
17. Patra, T.K. and P.N. Sheth, Biomass gasification models for downdraft gasifier: A stateof-the-art review. Renewable and Sustainable Energy Reviews, 2015. 50: p. 583-593.

18. Karmakar, M., et al., Investigation of fuel gas generation in a pilot scale fluidized bed autothermal gasifier using rice husk. Fuel, 2013. 111: p. 584-591.

19. Subbaiah, B.S., et al., Gasification of biomass using fluidized bed. International Journal of Innovative Research in Science, Engineering and Technology, 2014. 3(2): p. 8995-9002.

20. Singh, D., et al., Groundnut shell gasification performance in a fluidized bed gasifier with bubbling air as gasification medium. Environmental technology, 2018: p. 1-13.

21. Sarker, S., et al., Characterization and pilot scale fluidized bed gasification of herbaceous biomass: a case study on alfalfa pellets. Energy Conversion and Management, 2015. 91: p. 451-458.

22. Maglinao Jr, A.L., S.C. Capareda, and H. Nam, Fluidized bed gasification of high tonnage sorghum, cotton gin trash and beef cattle manure: evaluation of synthesis gas production. Energy conversion and management, 2015. 105: p. 578-587.

23. Hosseini, S.E., et al., A review on biomass- based hydrogen production for renewable energy supply. International Journal of Energy Research, 2015. 39(12): p. 1597-1615.

24. Kook, J.W., et al., Gasification and tar removal characteristics of rice husk in a bubbling fluidized bed reactor. Fuel, 2016. 181: p. 942-950.

25. Mohammed, M., et al., Air gasification of empty fruit bunch for hydrogen-rich gas production in a fluidized-bed reactor. Energy Conversion and Management, 2011. 52(2): p. $1555-1561$.

26. Ściążko, M. and L. Stępień, A Modified Gibbs Free Energy Minimisation Model for Fluid Bed Coal Gasification. Chemical and Process Engineering, 2015. 36(1): p. 73-87.

27. Pumiglia, D., et al., Aggravated test of Intermediate temperature solid oxide fuel cells fed with tar-contaminated syngas. Journal of Power Sources, 2017. 340: p. 150-159.

28. Woytiuk, K., et al., The effect of torrefaction on syngas quality metrics from fluidized bed gasification of SRC willow. Renewable Energy, 2017. 101: p. 409-416.

29. Wolff, D., E. Walsh, and K. McDonnell, Practical experience with woody biomass in a down-draft gasifier. Journal of Technology Innovations in Renewable Energy, 2013. 2(1): p. 47-52.

30. Volk, T.A., J.P. Heavey, and M.H. Eisenbies, Advances in shrub- willow crops for bioenergy, renewable products, and environmental benefits. Food and Energy Security, 2016. 5(2): p. 97-106.

31. Serapiglia, M.J., et al., Yield and woody biomass traits of novel shrub willow hybrids at two contrasting sites. BioEnergy Research, 2013. 6(2): p. 533-546.

32. García, R., et al., Biomass proximate analysis using thermogravimetry. Bioresource technology, 2013. 139: p. 1-4.

33. Nyakuma, B.B., et al., Thermogravimetric analysis of the fuel properties of empty fruit bunch briquettes. Jurnal Teknologi, 2014. 67(3). 
34. Pottmaier, D., et al., The profiles of mass and heat transfer during pinewood conversion. Energy Procedia, 2015. 66: p. 285-288.

35. González-Vázquez, M.P., et al., Comparison of the gasification performance of multiple biomass types in a bubbling fluidized bed. Energy Conversion and Management, 2018. 176: p. 309-323.

36. Motta, I.L., et al., Biomass gasification in fluidized beds: A review of biomass moisture content and operating pressure effects. Renewable and Sustainable Energy Reviews, 2018. 94: p. 998-1023.

37. Li, G., et al., Modeling of ash agglomerating fluidized bed gasifier using back propagation neural network based on particle swarm optimization. Applied Thermal Engineering, 2018. 129: p. 1518-1526.

38. Jordan, C.A. and G. Akay, Speciation and distribution of alkali, alkali earth metals and major ash forming elements during gasification of fuel cane bagasse. Fuel, 2012. 91(1): p. 253-263.

39. Ma, Z., et al., Gasification of rice husk in a downdraft gasifier: the effect of equivalence ratio on the gasification performance, properties, and utilization analysis of byproducts of char and tar. BioResources, 2015. 10(2): p. 2888-2902.

40. Adnan, M.A., et al., Gasification performance of Spirulina microalgae-A thermodynamic study with tar formation. Fuel, 2019. 241: p. 372-381.

41. Basu, P., Biomass gasification and pyrolysis: practical design and theory. 2010: Academic press.

42. Varma, A.K. and P. Mondal, Physicochemical characterization and pyrolysis kinetic study of sugarcane bagasse using thermogravimetric analysis. Journal of Energy Resources Technology, 2016. 138(5): p. 052205.

43. Nyakuma, B.B., et al. Thermogravimetric Analysis of Char Waste from the Air Gasification of Empty Fruit Bunch Briquette. in MATEC Web of Conferences. 2014. EDP Sciences.

44. Nyakuma, B.B., et al., Comparative analysis of the calorific fuel properties of Empty Fruit Bunch Fiber and Briquette. Energy Procedia, 2014. 52: p. 466-473.

45. Ahmad, A.A., et al., Assessing the gasification performance of biomass: A review on biomass gasification process conditions, optimization and economic evaluation. Renewable and Sustainable Energy Reviews, 2016. 53: p. 1333-1347.

46. Zhao, J., et al., TG-DSC analysis of straw biomass pyrolysis and release characteristics of noncondensable gas in a fixed-bed reactor. Drying technology, 2017. 35(3): p. 347-355.

47. Kaewluan, S. and S. Pipatmanomai, Potential of synthesis gas production from rubber wood chip gasification in a bubbling fluidised bed gasifier. Energy conversion and management, 2011. 52(1): p. 75-84.

48. Kim, Y.D., et al., Air-blown gasification of woody biomass in a bubbling fluidized bed gasifier. Applied energy, 2013. 112: p. 414-420. 
49. Guo, F., et al., Effect of design and operating parameters on the gasification process of biomass in a downdraft fixed bed: An experimental study. International Journal of Hydrogen Energy, 2014. 39(11): p. 5625-5633.

50. Monteiro, E., et al., Experimental and modeling studies of Portuguese peach stone gasification on an autothermal bubbling fluidized bed pilot plant. Energy, 2018. 142: p. 862-877.

51. González-Vázquez, M.d.P., et al., Unconventional biomass fuels for steam gasification: Kinetic analysis and effect of ash composition on reactivity. Energy, 2018. 155: p. 426437.

52. Karatas, H. and F. Akgun, Experimental results of gasification of walnut shell and pistachio shell in a bubbling fluidized bed gasifier under air and steam atmospheres. Fuel, 2018. 214: p. 285-292.

53. Pérez, N.P., et al., Fluid-dynamic assessment of sugarcane bagasse to use as feedstock in bubbling fluidized bed gasifiers. Applied thermal engineering, 2014. 73(1): p. 238-244.

54. Gao, N., A. Li, and C. Quan, A novel reforming method for hydrogen production from biomass steam gasification. Bioresource technology, 2009. 100(18): p. 4271-4277.

55. Acharya, B., A. Dutta, and P. Basu, An investigation into steam gasification of biomass for hydrogen enriched gas production in presence of $\mathrm{CaO}$. International Journal of Hydrogen Energy, 2010. 35(4): p. 1582-1589.

56. Liu, L., et al., Experimental study of biomass gasification with oxygen-enriched air in fluidized bed gasifier. Science of the Total Environment, 2018. 626: p. 423-433.

57. Diyoke, C., et al., Modelling of down-draft gasification of biomass-An integrated pyrolysis, combustion and reduction process. Applied Thermal Engineering, 2018. 142: p. 444-456.

58. Rapagnà, S., et al., Steam-gasification of biomass in a fluidised-bed of olivine particles. Biomass and Bioenergy, 2000. 19(3): p. 187-197.

59. Makwana, J., et al., Air gasification of rice husk in bubbling fluidized bed reactor with bed heating by conventional charcoal. Bioresource technology, 2015. 178: p. 45-52.

60. Kaewluan, S. and S. Pipatmanomai, Gasification of high moisture rubber woodchip with rubber waste in a bubbling fluidized bed. Fuel Processing Technology, 2011. 92(3): p. 671677.

61. Meng, F., et al., Effect of gasifying agents on sawdust gasification in a novel pilot scale bubbling fluidized bed system. Fuel, 2019. 249: p. 112-118.

62. Shehzad, A., et al., Modeling and comparative assessment of bubbling fluidized bed gasification system for syngas production-a gateway for a cleaner future in Pakistan. Environmental technology, 2018. 39(14): p. 1841-1850.

63. Hamad, M.A., et al., Hydrogen rich gas production from catalytic gasification of biomass. Renewable Energy, 2016. 85: p. 1290-1300.

64. Ahmed, R., et al., Thermodynamics analysis of refinery sludge gasification in adiabatic updraft gasifier. The Scientific World Journal, 2014. 2014. 


\section{List of Tables}

Table 1. Proximate and ultimate analysis of SRC willow chips.

\begin{tabular}{|c|c|c|c|c|c|c|c|c|c|c|}
\hline & \multicolumn{9}{|c|}{ Ultimate analysis (wt \%) } & \multicolumn{5}{c|}{ Proximate analysis (wt \%) } \\
\hline Biomass fuel & $\mathrm{C}$ & $\mathrm{H}$ & $\mathrm{N}$ & $\mathrm{O}^{\mathrm{b}}$ & $\mathrm{S}$ & $\mathrm{M}$ & $\mathrm{VM}$ & $\mathrm{FC}$ & Ash & $\mathrm{LHV}\left(\mathrm{MJ} / \mathrm{m}^{3}\right)$ \\
\hline SRC willow chips & 45.4 & 5.7 & 0.8 & 48 & 0.1 & 2.9 & 82.5 & 12.9 & 1.7 & 4.4 \\
\hline
\end{tabular}

M - Moisture; VM - Volatile matter; FC - Fixed carbon.

${ }^{\text {a }}$ On dry-ash-free basis.

${ }^{\mathrm{b}}$ Calculated by the difference.

${ }^{\mathrm{c}}$ On dry basis except for moisture which is on an as received basis.

${ }^{\mathrm{d}}$ Low heating value (dry) 
Table 2. Operating conditions of bubbling fluidized bed biomass gasifier (BFBBG).

\begin{tabular}{|l|c|}
\hline Equivalent Ratio (ER) & $0.25,0.29$ and 0.32 \\
\hline Gasification air flow rate $(\mathrm{L} / \mathrm{m})$ & $45,65,80$ \\
\hline Hopper air flow rate $(\mathrm{L} / \mathrm{m})$ & 3 \\
\hline Fluidization velocity $(\mathrm{m} / \mathrm{s})$ & $2469.6,2126.8$ and 1920.9 \\
\hline Feeding rate $(\mathrm{g} / \mathrm{h})$ & $650-850$ \\
\hline Heater temperature setup $\left({ }^{\circ} \mathrm{C}\right)$ & $10,11,12.5$ \\
\hline Screw feeder motor frequency $(\mathrm{Hz})$ & \\
\hline Silica sand $\mathrm{particle} \mathrm{size}$ & $212-300$ \\
Dimension $(\mu \mathrm{m})$ & 1520 \\
Density $\left(\mathrm{kg} / \mathrm{m}^{3)}\right.$ & \\
\hline
\end{tabular}


Table 3. Major recations of gasification.

\begin{tabular}{|l|l|c|}
\hline \multicolumn{1}{|c|}{ Reaction name } & \multicolumn{1}{|c|}{ Reactions } & $\Delta \mathbf{H}^{\mathbf{0}}(\mathbf{K J} / \mathbf{m o l})$ \\
\hline Oxidation & $\mathrm{C}(\mathrm{s})+\mathrm{O}_{2} \leftrightarrow \mathrm{CO}_{2}$ & $-394.0^{\mathrm{a}}$ \\
& $\mathrm{C}(\mathrm{s})+1 / 2 \mathrm{O}_{2} \leftrightarrow \mathrm{CO}$ & $-123.0^{\mathrm{a}}$ \\
\hline Boudouard & $\mathrm{C}(\mathrm{s})+\mathrm{CO}_{2} \leftrightarrow 2 \mathrm{CO}$ & $+172.0^{\mathrm{b}}$ \\
\hline Water gas & $\mathrm{C}(\mathrm{s})+\mathrm{H}_{2} \mathrm{O} \leftrightarrow \mathrm{CO}+\mathrm{H}_{2}$ & $+131.0^{\mathrm{b}}$ \\
& $\mathrm{C}(\mathrm{s})+2 \mathrm{H}_{2} \mathrm{O} \leftrightarrow \mathrm{CO} 2+2 \mathrm{H}_{2}$ & $+771.0^{\mathrm{b}}$ \\
\hline Methanation & $\mathrm{C}(\mathrm{s})+2 \mathrm{H}_{2} \leftrightarrow \mathrm{CH} \mathrm{CH}_{4}$ & $-41.0^{\mathrm{a}}$ \\
\hline Water gas shift & $\mathrm{CO}+\mathrm{H}_{2} \mathrm{O} \leftrightarrow \mathrm{CO}+\mathrm{H}_{2}$ & $+206.0^{\mathrm{b}}$ \\
\hline Steam reforming & $\mathrm{CH}+\mathrm{H}_{2} \mathrm{O} \leftrightarrow \mathrm{CO}+3 \mathrm{H}_{2}$ & \\
\hline
\end{tabular}

a Negative sign indicates the exothermic reactions.

${ }^{\mathrm{b}}$ Positive sign indicates the endothermic reactions. 
Table 4. Product gas analysis and gasifier performance of SRC willow chips

\begin{tabular}{|c|c|c|c|}
\hline Feedstock & \multicolumn{3}{|c|}{ SRC willow chips } \\
\hline $\mathbf{E R}$ & 0.25 & 0.29 & 0.32 \\
\hline Feeding rate $(\mathrm{g} / \mathrm{h})$ & 2469.6 & 2126.8 & 1920.9 \\
\hline \multicolumn{4}{|c|}{ Product gas composition (Vol \%) } \\
\hline \multirow{2}{*}{$\mathrm{H}_{2}$} & $9.95^{\mathrm{a}}$ & $8.26^{\mathrm{a}}$ & $6.30^{\mathrm{a}}$ \\
\hline & $8.96^{\mathrm{b}}$ & $8.31^{b}$ & $6.53^{\mathrm{b}}$ \\
\hline \multirow{2}{*}{$\mathrm{CO}$} & $16.98^{\mathrm{a}}$ & $14.20^{\mathrm{a}}$ & $12.72^{\mathrm{a}}$ \\
\hline & $16.64^{\mathrm{b}}$ & $14.50^{\mathrm{b}}$ & $12.29^{b}$ \\
\hline \multirow{2}{*}{$\mathrm{CH}_{4}$} & $4.43^{\mathrm{a}}$ & $3.94^{\mathrm{a}}$ & $3.88^{\mathrm{a}}$ \\
\hline & $4.67^{\mathrm{b}}$ & $4.06^{\mathrm{b}}$ & $4.22^{b}$ \\
\hline \multirow{2}{*}{$\mathrm{CO}_{2}$} & $17.49^{\mathrm{a}}$ & $18.16^{\mathrm{a}}$ & $19.21^{\mathrm{a}}$ \\
\hline & $17.99^{b}$ & $18.16^{\mathrm{b}}$ & $18.24^{b}$ \\
\hline $\operatorname{LHV}\left(\mathrm{MJ} / \mathrm{m}^{3}\right)$ & 4.37 & 3.89 & 3.67 \\
\hline CGE $(\%)$ & 49.63 & 47.89 & 46.43 \\
\hline $\mathrm{CCE}(\%)$ & 90.68 & 95.48 & 95.76 \\
\hline Gas yield $\left(\mathrm{m}^{3} / \mathrm{h}\right)$ & 3.93 & 4.17 & 4.55 \\
\hline Tar yield $\left(\mathrm{g} / \mathrm{m}^{3}\right)$ & 16.78 & 12.45 & 7.24 \\
\hline
\end{tabular}

Online analysis ${ }^{\mathrm{a}}$

GC analysis ${ }^{b}$ 


\section{List of Figures}
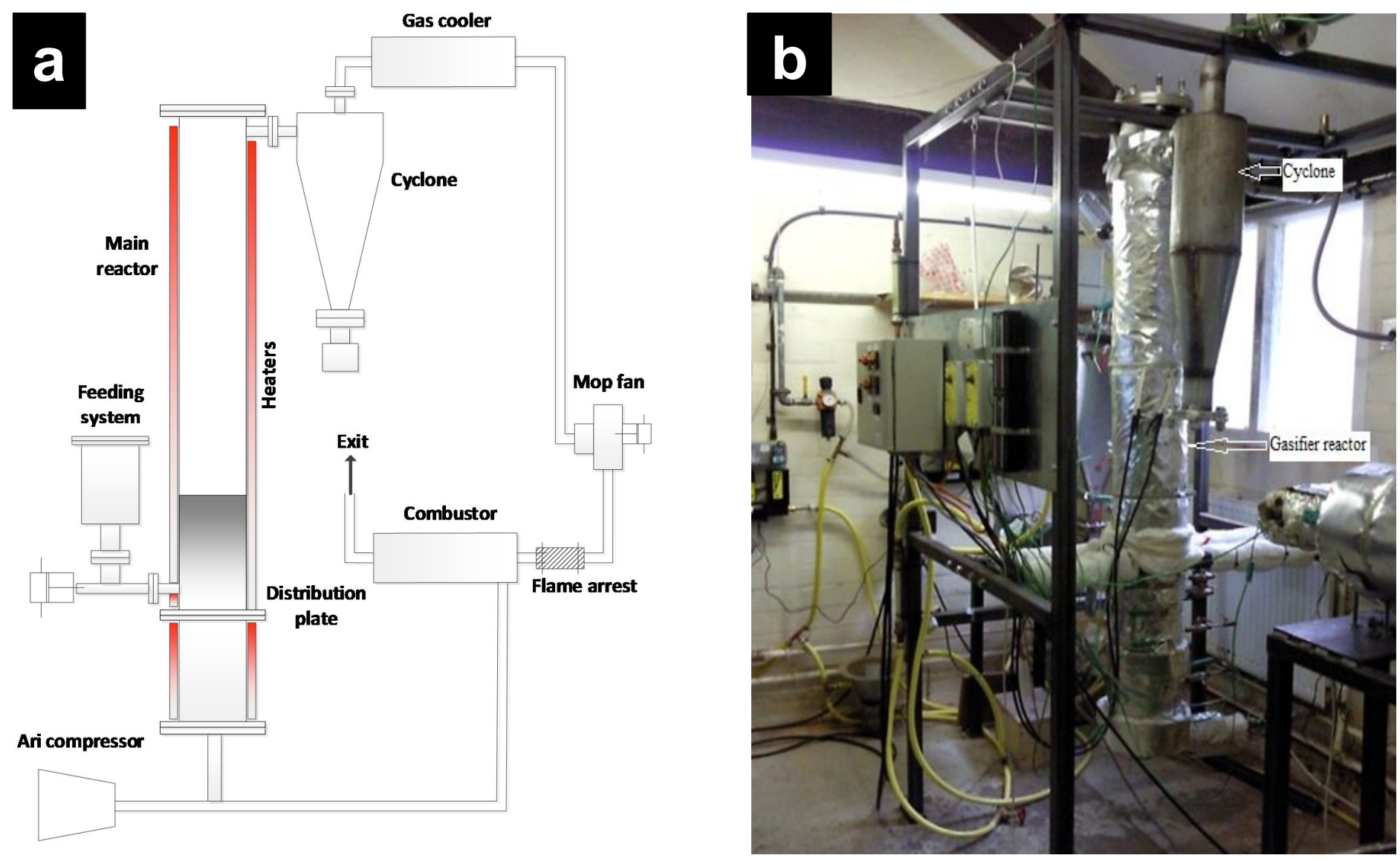

Fig. 1. (a) Schematic diagram of bubbling fluidized bed biomass gasifier; (b) Experimental set up of bubbling fluidized bed reactor and cyclone. 

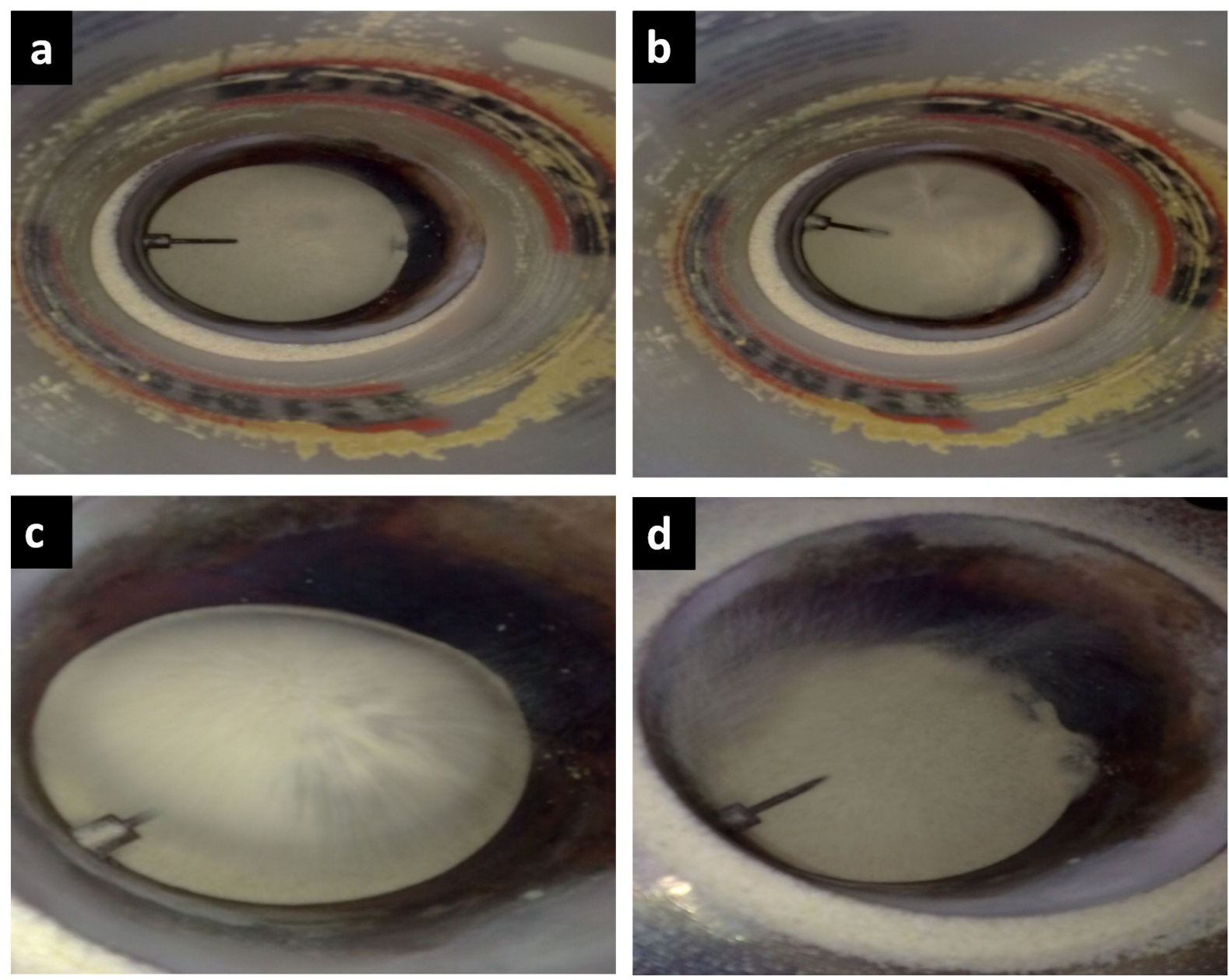

Fig. 2. (a) Bed material in the reactor, (b) Bubble initiation in the reactor, (c) Air bubble rising in the reactor and (d) Air bubble burst in the reactor. 


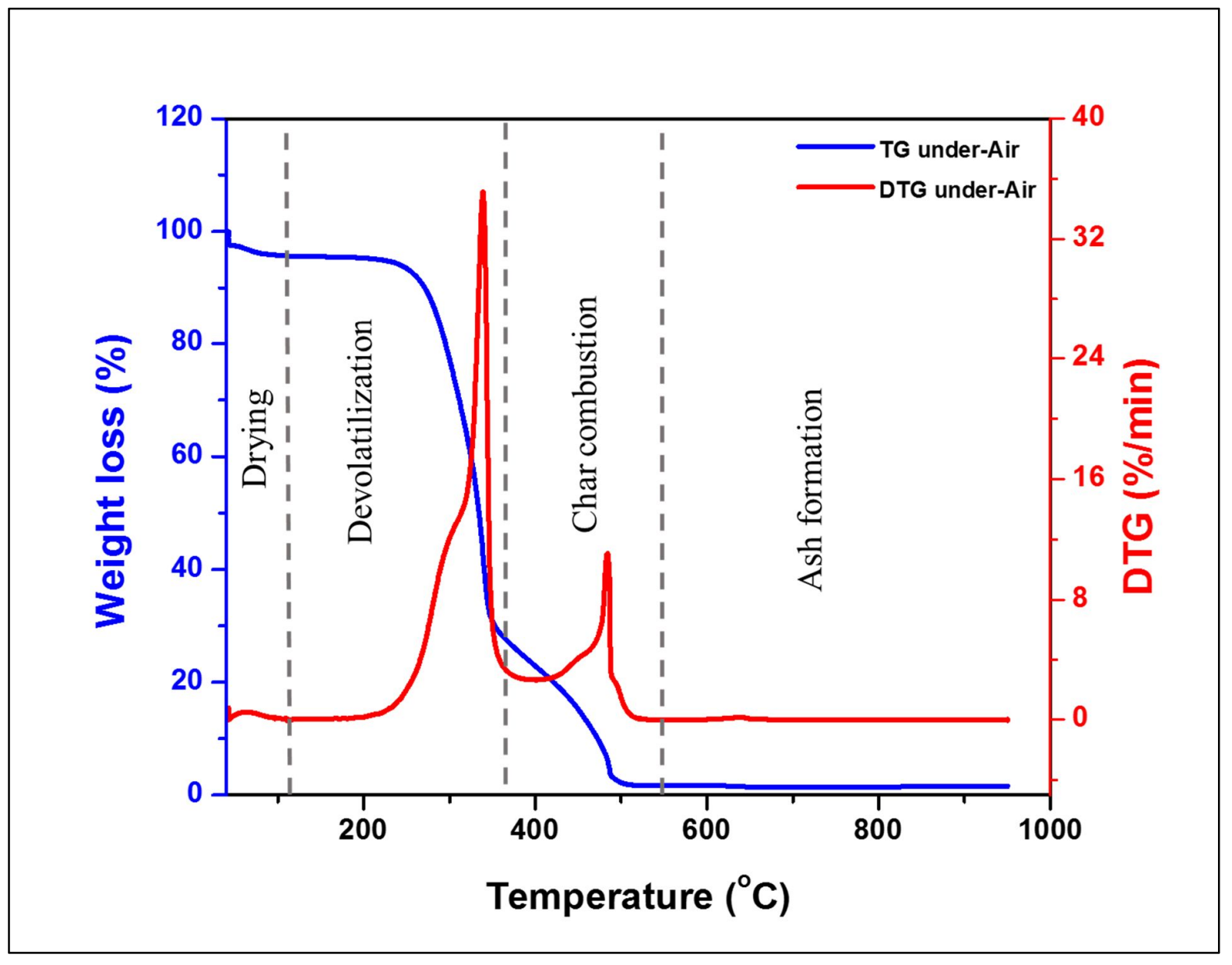

Fig. 3. TG/DTG curves of SRC willow woodchips under air. 


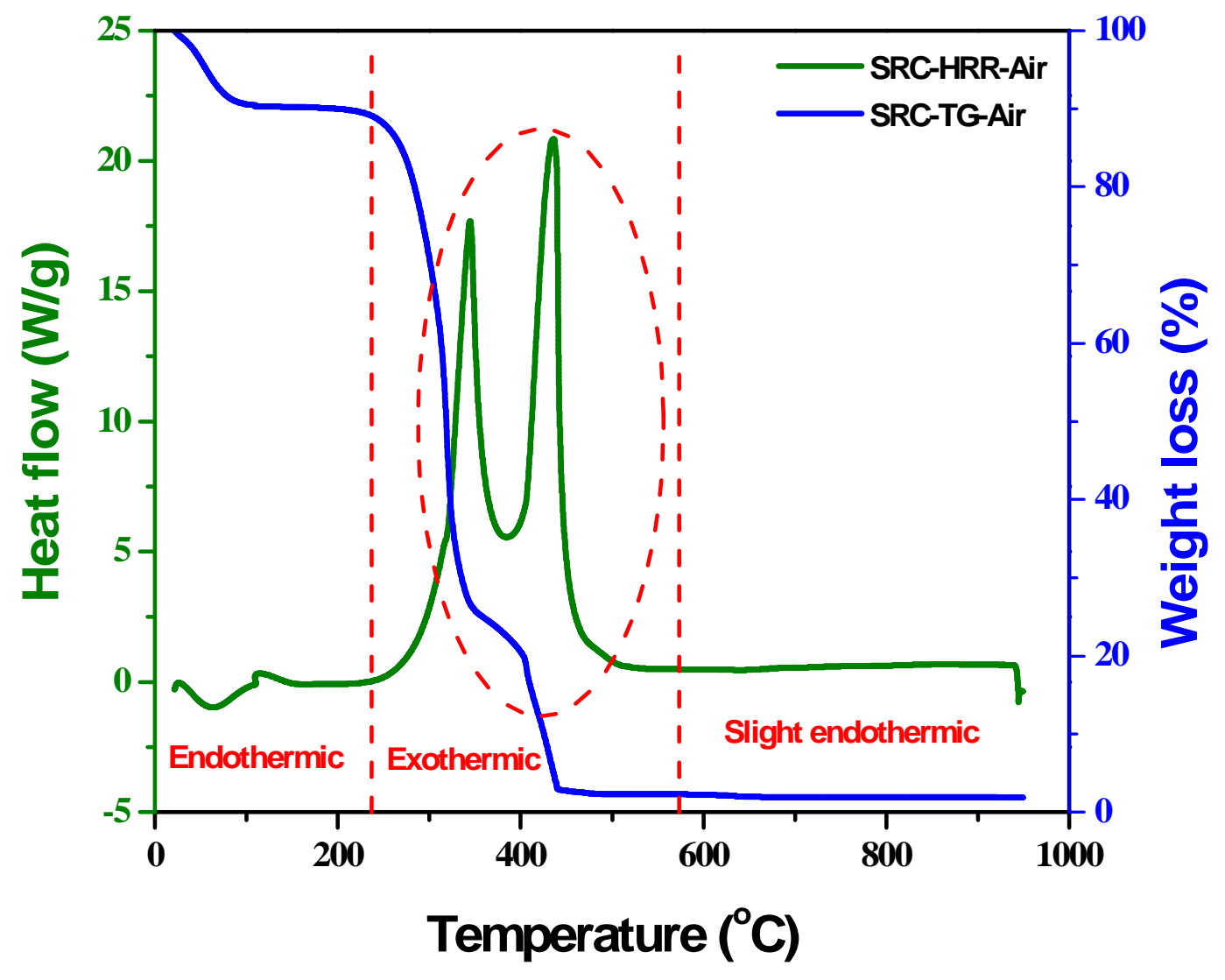

Fig. 4. Heat transfer profile of SRC willow woodchips conversion under air. 


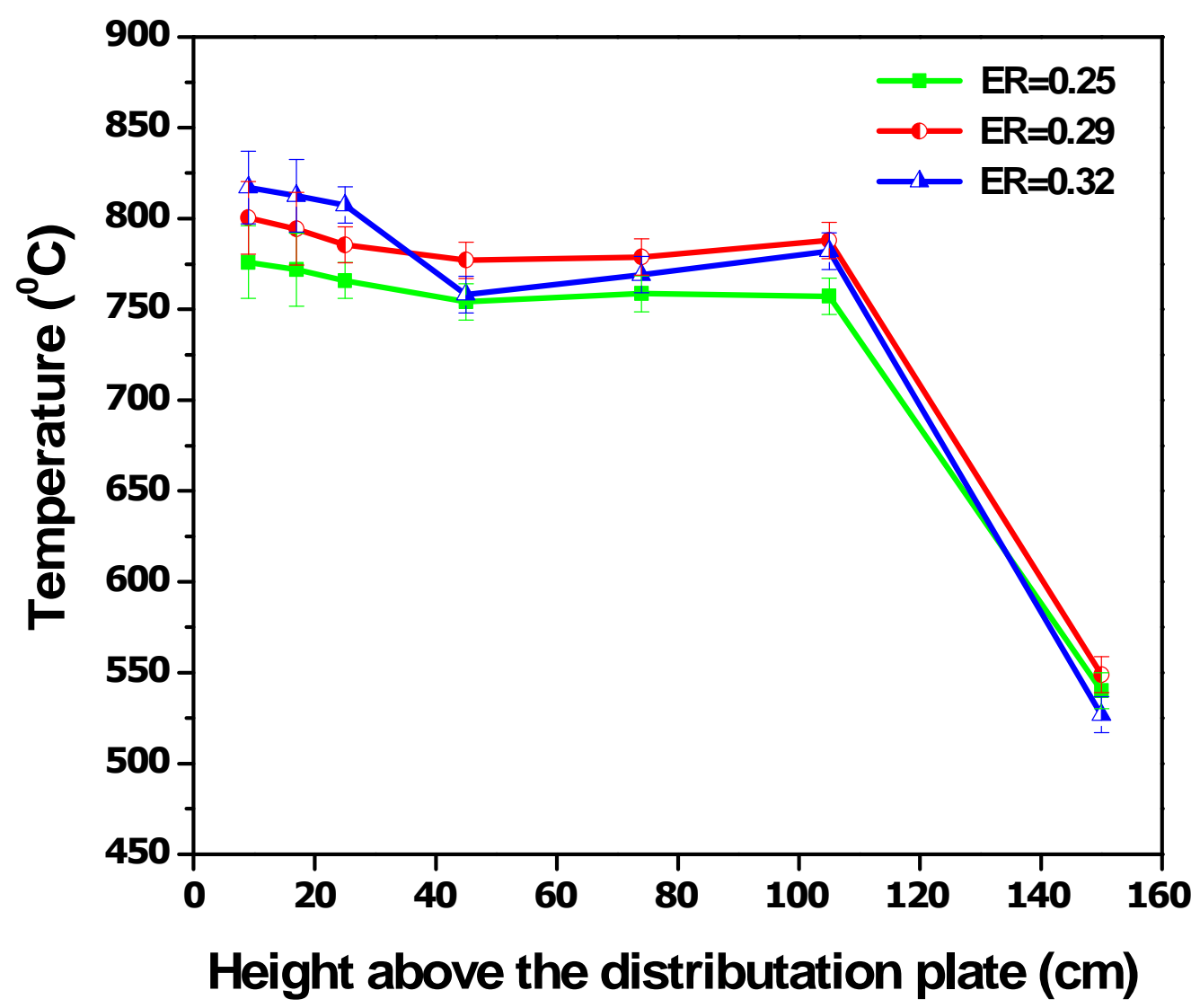

Fig. 5. Effect of temperature along the height of reactor at different ERs. 

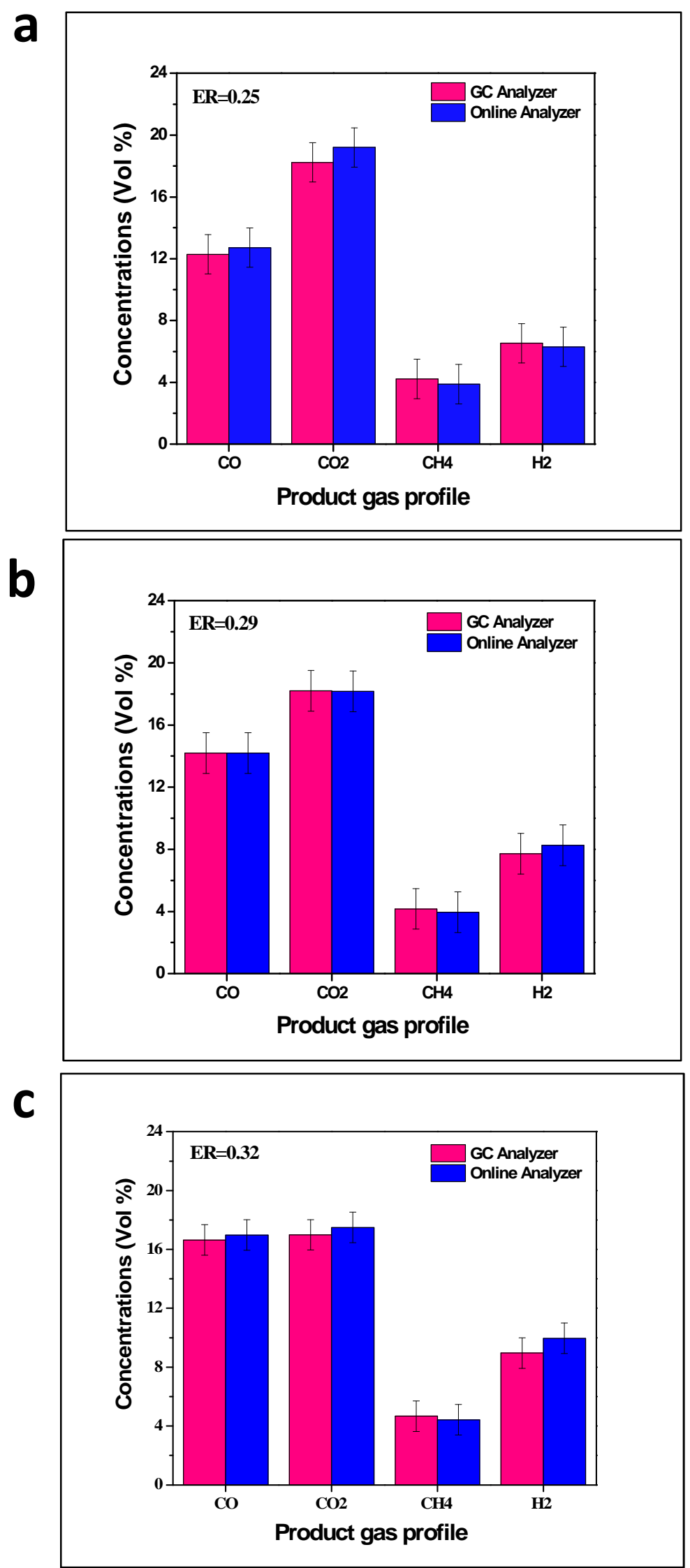

Fig. 6. Effect of different equivalence ratios on the product gas concentrations along with the comparison of GC and online analysis; (a) 0.25 ER, (b) $0.29 \mathrm{ER}$ and (c) 0.32 ER. 


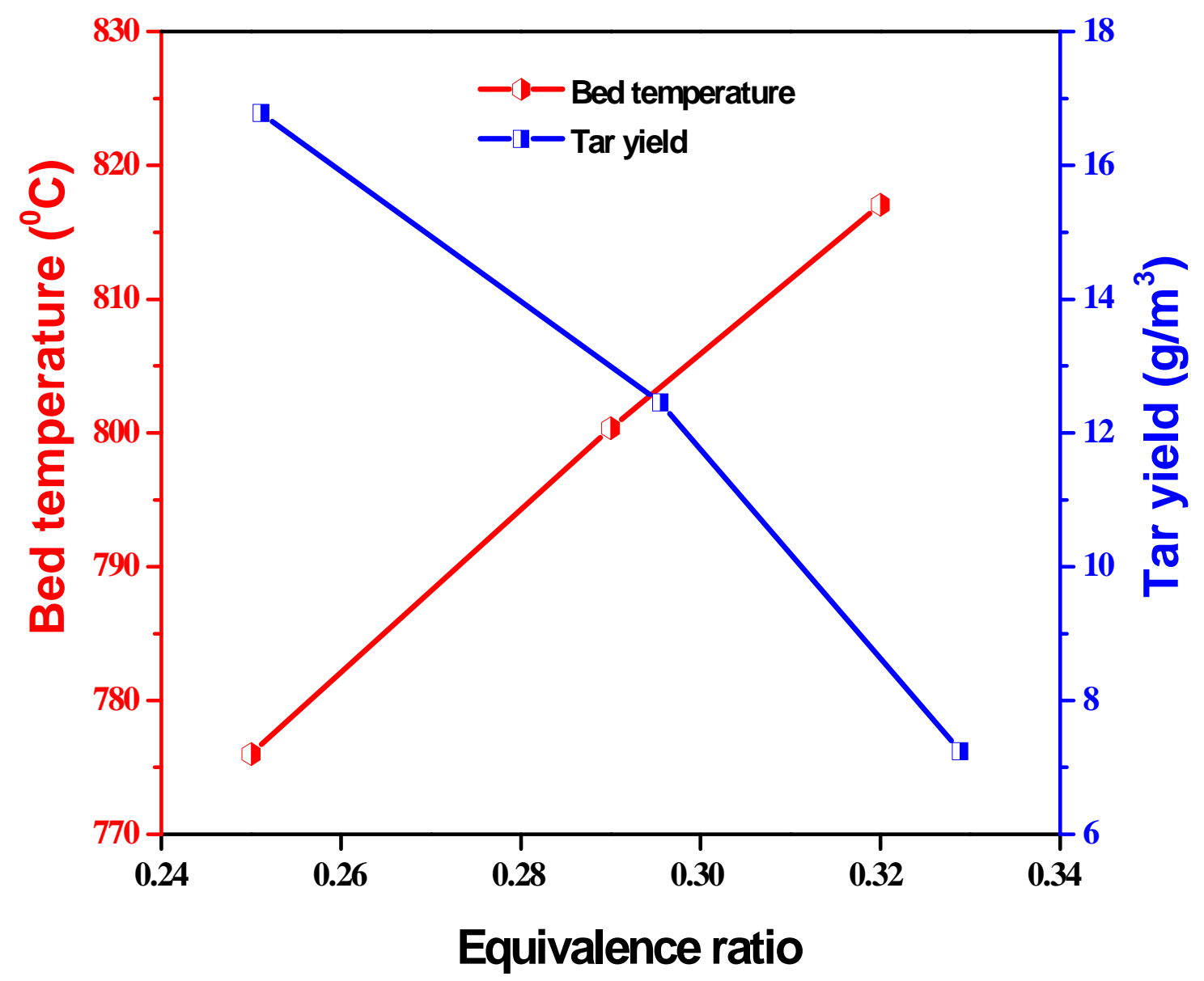

Fig. 7. Effect of equivalence ratio (ER) on bed temperature and tar yield. 


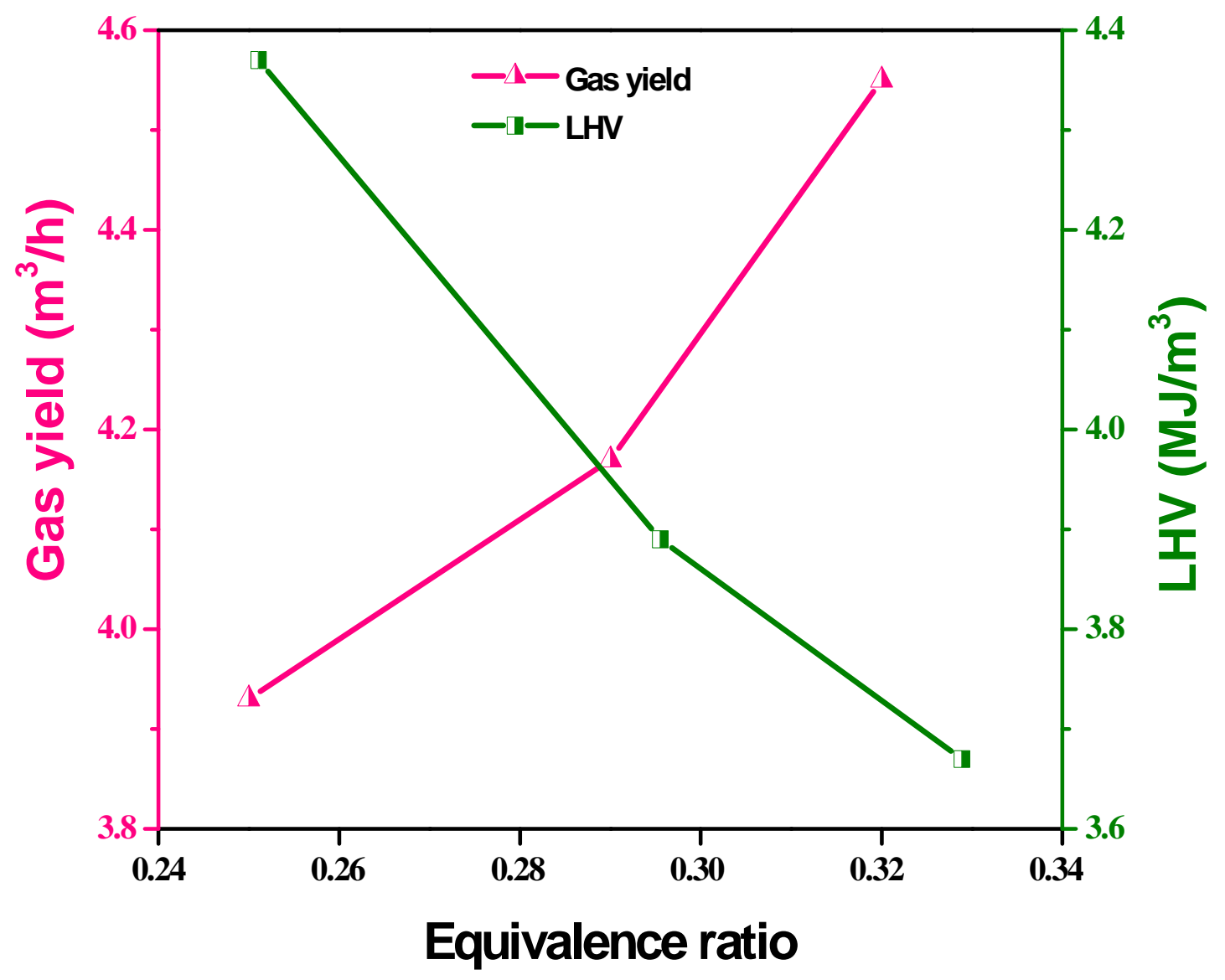

Fig. 8. Effect of equivalence ratio (ER) on gas yield and LHV. 


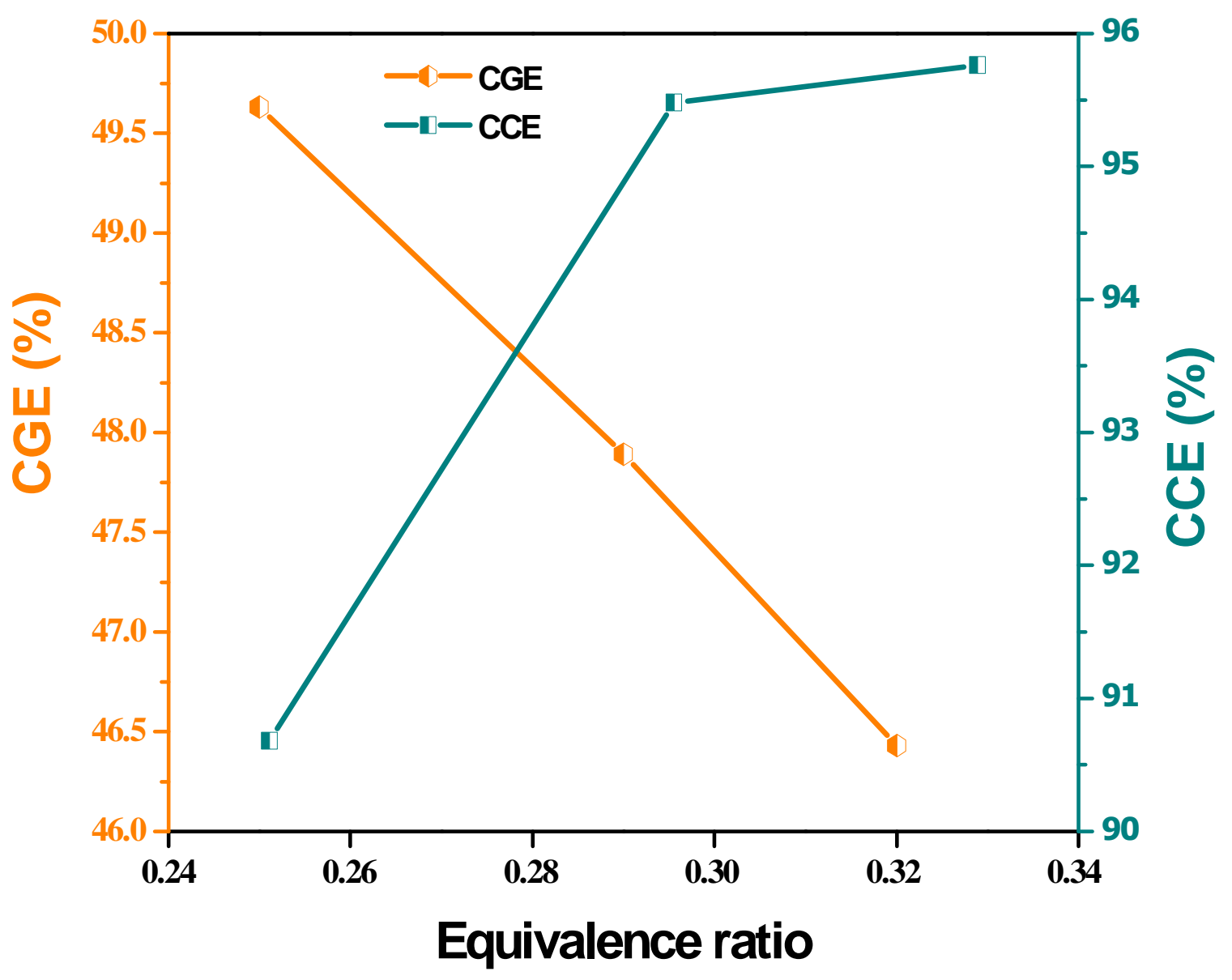

Fig. 9. Effect of equivalence ratio (ER) on CGE and CCE. 